\title{
AUTOMATIC ESTIMATION OF DYNAMICS OF IONOSPHERIC DISTURBANCES WITH 1-15 MINUTE LIFETIMES AS DERIVED FROM ISTP SB RAS FAST CHIRP IONOSONDE DATA
}

\section{O.I. Berngardt}

Institute of Solar-Terrestrial Physics SB RAS, Irkutsk, Russia, berng@iszf.irk.ru

\section{T.V. Bubnova}

Institute of Solar-Terrestrial Physics SB RAS, Irkutsk,Russia,btv@iszf.irk.ru

\author{
A.V. Podlesnyi \\ Institute of Solar-Terrestrial Physics SB RAS, \\ Irkutsk,Russia,pav1986@rambler.ru
}

\begin{abstract}
We propose and test a method of analyzing ionograms of vertical sounding, which is based on detecting deviations of the shape of an ionogram from its regular (averaged) shape. We interpret these deviations in terms of reflection from electron density irregularities at heights corresponding to the effective height. We examine the irregularities thus discovered within the framework of a model of a localized uniformly moving irregularity, and determine their characteristic parameters: effective heights and observed vertical velocities. We analyze selected experimental data for three seasons (spring, winter, autumn) obtained nearby Irkutsk with the ISTP SB RAS fast chirp ionosonde in 2013-2015.
\end{abstract}

The analysis of six days of observations conducted in these seasons has shown that in the observed vertical drift of the irregularities there are two characteristic distributions: wide velocity distribution with nearly 0 $\mathrm{m} / \mathrm{s}$ mean and with standard deviation of $\sim 250 \mathrm{~m} / \mathrm{s}$ and narrow distribution with nearly $-160 \mathrm{~m} / \mathrm{s}$ mean. The analysis has demonstrated the effectiveness of the proposed algorithm for the automatic analysis of vertical sounding data with high repetition rate.

Keywords: Ionospheric disturbances, automatic ionogram processing, ionospheric vertical sounding.

\section{INTRODUCTION}

Ionospheric plasma is a highly dynamic medium with natural irregularities of various scales and types from centimeter thermal irregularities, used for plasma diagnostics by an incoherent scatter technique, to diurnal variations associated with Earth rotation. Ionospheric irregularities with lifetimes from a minute and more have been studied for a long time by various methods and instruments: GPS/GLONASS networks, ionosondes and their networks, satellites and radars.

The main mechanisms of formation of large-scale irregularities with periods of tens of minutes and more include internal atmospheric waves propagating from various sources mainly in a horizontal direction [Hocke, Schlegel, 1996; Frissell et al., 2016].

Irregularities with periods 1-15 min are less studied and are currently being actively investigated [Kozlovsky et al., 2013]. These irregularities are sometimes associated with acoustic waves from various powerful sources and can propagate from a source both horizontally [Berngardt et al., 2015a] and vertically [Maruyama et al., 2016a, 2016b; Berngardt et al., 2015b, 2017].

Ionosondes have been used for studying the ionosphere for a very long time. Regular 15-min modes of operation of the worldwide network of ionosondes have been put into operation; networks of ionosondes of different types both with pulsed [Reinisch et al., 2009] and with continuous transmitted signals (see, e.g., [Ponyatov et al., 1999; Uryadov et al., 2004] and references therein) have been created. Long-term ionosonde measure- ments form a basis for the development of modern ionospheric plasma models at heights below the F2-layer maximum and are used for constructing models, which are corrected in real time [Bilitza et al., 2017; Pignalberi et al., 2018], as well as for selective [Liu et al., 2011; Maruyama et al., 2011, 2016a, 2016b; Berngardt et al., 2015b] and statistical studies of ionospheric irregularities [Kurkin et al., 2014; Berngardt et al., 2017; Givishvili, Leshchenko, 2017].

The development of ionosondes in the last few years is associated in particular with the development of methods for digital formation of transmitted signals and direct digital reception of received signals. This has greatly simplified the development of fast ionosondes working with a higher time resolution (1 min or less). The increase in the temporal resolution of ionospheric processes has shown a significant proportion of shortlived ionospheric irregularities and has revealed considerable difficulties in interpreting ionograms. The complexity of interpreting ionograms and the large data flow stimulate the development of ionogram processing techniques aimed at detecting irregularities of different scales and determining their characteristics rather than at solving the problem of reconstructing the vertical electron density profile [Haldoupis et al., 2006; Jiang et al., 2015]. Further in the paper, we will use a similar approach.

Manifestations of single irregularities in an individual ionosonde are often similar [Lobb, Titheridge, 1977; Golikova et al, 2005; Kurkin et al., 2014] and differ 
mainly in the duration of observation of the effect and in the observed vertical velocity of a disturbance on an ionogram. The observed vertical velocity is related not only to the group or phase velocity of an irregularity, but also to the drift direction and to the difference in the actual height, at which the irregularity exists, from the effective height measured by the ionosonde.

Further, we will examine irregularities that appear as essential quick additional tracks on ionograms or significant distortions of the main track whose characteristic lifetime (i.e., the time during which the disturbance of the track shape may be considered to have constant shape and height) is $1-15 \mathrm{~min}$.

We propose and test a method of analyzing vertical ionograms, which is based on the identification of deviations of the shape of an ionogram from its regular (averaged over 15 min) shape. The increased temporal resolution of the ionosonde allows us to consider the background ionosphere at the averaging period to be stationary and to persistently find tracks of 1-15 min ionospheric irregularities on ionograms. Using the proposed method and data from the ISTP SB RAS fast chirp ionosonde, located near Irkutsk [Podlesny, 2017; Naumenko, Podlesny, 2017], we have obtained the statistics of the distribution of irregularities by observed velocities for a given region; we have shown that there is an appreciable number of 1-15 min irregularities moving downward with a characteristic observed vertical velocity of $\sim 160 \mathrm{~m} / \mathrm{s}$, which in the first approximation does not depend on season.

\section{METHOD OF IDENTIFYING SHORT-LIVED

The proposed processing method is based on the identification of the average shape of an ionogram during an averaging period (hereinafter, 15 and $30 \mathrm{~min}$ ), which includes features whose lifetimes are of the order of and more than this period. Among these features may be regular features of an ionogram associated with the well-studied reflection from a smoothly inhomogeneous layer, as well as irregular features of ionospheric plasma with a lifetime comparable to the averaging period (multiple reflections from the ionosphere, scattering by sporadic long-lived structures - F scattering, scattering by the sporadic E layer, etc.).

To eliminate slow (quasistationary) effects, twostage filtering is used. The initial ionogram $A_{\mathrm{t}}\left(f, h_{\mathrm{eff}}\right)$, taken at moment $t$, is the dependence of the amplitude $A$ on the effective height $h_{\text {eff }}$ (group delay) of received (reflected and scattered) signals and on the sounding frequency $f$. In the analysis, it is represented as a matrix along the vertical axis of which is the group delay of a signal (the effective height of reflection $h_{\text {eff }}$ ); along the horizontal axis, the sounding frequency of a signal $f$; and the matrix element is the amplitude of a received signal A. A frequency spacing of the initial matrix is
$0.02 \mathrm{MHz}$, and a height spacing is $1.2 \mathrm{~km}$. We record one ionogram per minute, thus obtaining a sequence of 1440 matrices (ionograms) per day.

A typical time scale of regular ionospheric variations is $\sim 15 \mathrm{~min}$. This temporal resolution underpins the functioning of most ionosondes and their networks. Therefore, the ionogram averaged over 15 min can be considered to reflect the result of sounding of the undisturbed background ionosphere. Significant deviations of each ionogram from such an "average" ionogram are associated with short-living (or traveling) ionospheric irregularities of different nature. To detect them, we filter the sequence of ionograms.

At the first stage of the filtration, we use the initial ionogram to construct a mask of a stationary ionogram with a stationarity time of $5 \mathrm{~min}$ to leave only shortliving details including both irregularities and noise. The mask is constructed on a grid with a step of 0.1 $\mathrm{MHz}$ in frequency and $10 \mathrm{~km}$ in height as follows. Each element of the mask is set equal to 1 if there is at least one ionogram point with a significant amplitude (exceeding the average radio noise level in the receiver band estimated at the primary processing stage) in this element. If in $k$ of $m$ cases (3 of 5) this mask element remains equal to 1 , then all parts of the ionogram, which the element covers, are assigned 0 in the final ionogram, thereby removing permanent tracks from the ionogram. Qualitative estimates show that such a filtration corresponds to the elimination of reflections from irregularities traveling with vertical phase velocities less than 30 $\mathrm{m} / \mathrm{s}$.

At the second stage, from the resulting ionogram we remove the spot noise. In this stage of filtration, we use a cellular automata principle [Toffoli, Margolus, 1987].

From the ionogram, we remove all noise points that are not centers of regions of the points with significant amplitude. An ionogram point is taken to be a regular signal and is further considered in the analysis of irregularities if the significant amplitude is observed more than three times in eight neighboring cells and in the central cell. Otherwise (the significant amplitude is fixed in less than three neighboring cells), this point is considered to be noise and its value is ignored in the analysis of irregularities.

As a result of the two-stage filtration, the obtained ionograms $\tilde{A}_{\mathrm{t}}\left(f, h_{\mathrm{eff}}\right)$ contain only short-living variations without permanent or noise tracks. The frequency integration of the obtained ionogram for each height allows us to estimate the heights at which irregularities are observed at a given time.

Figure 1 presents the results of January 01, 2015 sounding derived from fast chirp ionosonde data (ISTP SB RAS Geophysical Observatory, the village of Tory) from 05:40 to 05:47 UT. There is (Figure 1) a vertical drift of the ionospheric irregularity encircled by a dashed line.

Figure 2 shows ionograms obtained by applying the above filtering algorithm to the ionograms of Figure 1. The comparison of Figures 1 and 2 indicates that the filtration effectively removes regular traces, leaving unaltered rapidly changing traces, which correspond to traveling irregularities (05:40-05:47 UT). 
For further analysis, we use maps of integrated amplitude $B\left(h_{\mathrm{eff}}, t\right)$ within the frequency range of the ionogram analysis $\left[f_{\min }, f_{\max }\right]$ :

$$
B\left(h_{\text {eff }}, t\right)=\frac{1}{f_{\text {max }}-f_{\text {min }}} \int_{f_{\min }}^{f_{\max }} \tilde{A}_{t}\left(f, h_{\text {eff }}\right) d f .
$$

The analysis of the $B\left(h_{\text {eff }}, t\right)$ maps allows us to determine heights at which the amplitude of a signal reflected from an ionospheric irregularity is maximal. Assuming that the position of the $B\left(h_{\mathrm{eff}}, t\right)$ maxima corresponds to the effective height and time of appearance of irregularities, we can perform their qualitative analysis.

The method of identifying irregularities has been tested using data on three seasons, excluding summer (32 days in total): February 13-15, 2013, April 15-17, 2013, April 19-21, 2013, May 23-25, 2013, September 23-25, 2013, October 24-26., 2013, April 24-26., 2015, May 11-13, 2015, November 13-15, 2015, December 06-08, 2015. Figure $3, a-f$ shows the $B\left(h_{\mathrm{eff}}, t\right)$ maps for different seasons derived from ionograms. The qualitative analysis has shown that the observed irregularities differ significantly in their lifetimes. The preliminary analysis has revealed that the irregularities can be divided into isolated (area II in Figure 3, $b$ ) and quasiperiodic (area I in Figure 3, b) disturbances. Examples of the quasiperiodic and isolated ionospheric irregularities are given in Figure 3, $g$ and $h$ respectively.

\section{OBSERVED \\ VERTICAL VELOCITY OF IRREGULARITIES}

One of the obvious parameters that can be estimated from such ionograms is the observed vertical velocity of irregularities. It is apparent that determining the ve- locity as well as the height of an irregularity is an inaccurate operation, especially at large heights, where the group delay of a signal is not proportional to height. In addition, the estimated velocity differs significantly from the group velocity of irregularities in case of their non-vertical drift and from the phase velocity in a vertical direction because we analyze the effective height of radio wave reflection rather than the real one.

However, to qualitatively evaluate the dynamics of irregularities in the first approximation, it is worth studying such observed vertical velocities.

We use the integrated amplitude maps for detecting irregularities and determining parameters of their drift. Assuming that the observed vertical velocity is constant, we can estimate these parameters.

Supposing the irregularity in a period $\left[T_{0}, T_{0}+\Delta T_{0}\right]$ to be localized in height and to be single, we can determine the velocity $V_{0}$ and the initial height of the irregularity $h_{\text {eff, } 0}$ from the condition of functional maxima:

$$
\begin{aligned}
& \Omega\left(T_{0}\right)= \\
& =\frac{1}{\Delta T_{0}} \int_{T_{0}}^{T_{0}+\Delta T_{0}} B\left(h_{\text {eff }, 0}+V_{0}\left(t-T_{0}\right), t\right) d t=\max .
\end{aligned}
$$

The average moment of observation of an irregularity

$$
T_{1}=\frac{\int_{T_{0}}^{T_{0}+\Delta T_{0}} B\left(h_{\text {eff }, 0}+V_{0}\left(t-T_{0}\right), t\right) t d t}{\int_{T_{0}}^{T_{0}+\Delta T_{0}} B\left(h_{\text {eff, } 0}+V_{0}\left(t-T_{0}\right), t\right) d t}
$$

and its lifetime

$$
\Delta T=\sqrt{\frac{\int_{T_{0}}^{T_{0}+\Delta T_{0}} B\left(h_{\mathrm{eff}, 0}+V_{0}\left(t-T_{0}\right), t\right)\left(t-T_{1}\right)^{2} d t}{\int_{T_{0}}^{T_{0}+\Delta T_{0}} B\left(h_{\mathrm{eff}, 0}+V_{0}\left(t-T_{0}\right), t\right) d t}}
$$
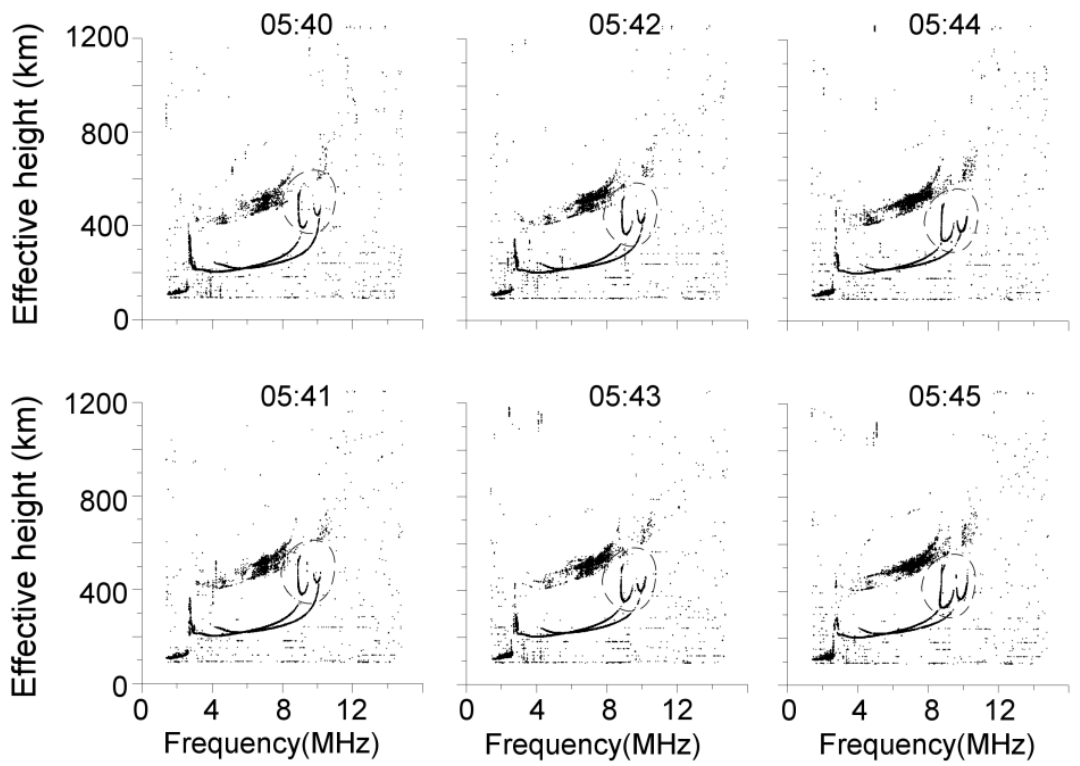

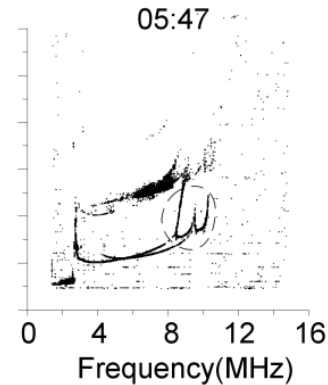

05:46

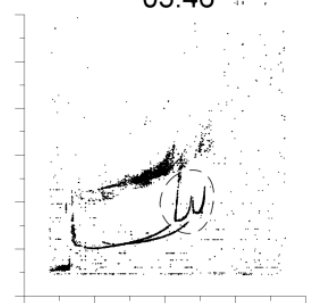

$05: 47$

Frequency $(\mathrm{MHz})$

Figure 1. Ionograms from the chirp ionosonde (ISTP SB RAS Geophysical Observatory, the village of Tory) for the period from 05:40 to 05:47 UT on January 01, 2015 in the presence of an ionospheric irregularity (dashed line) 

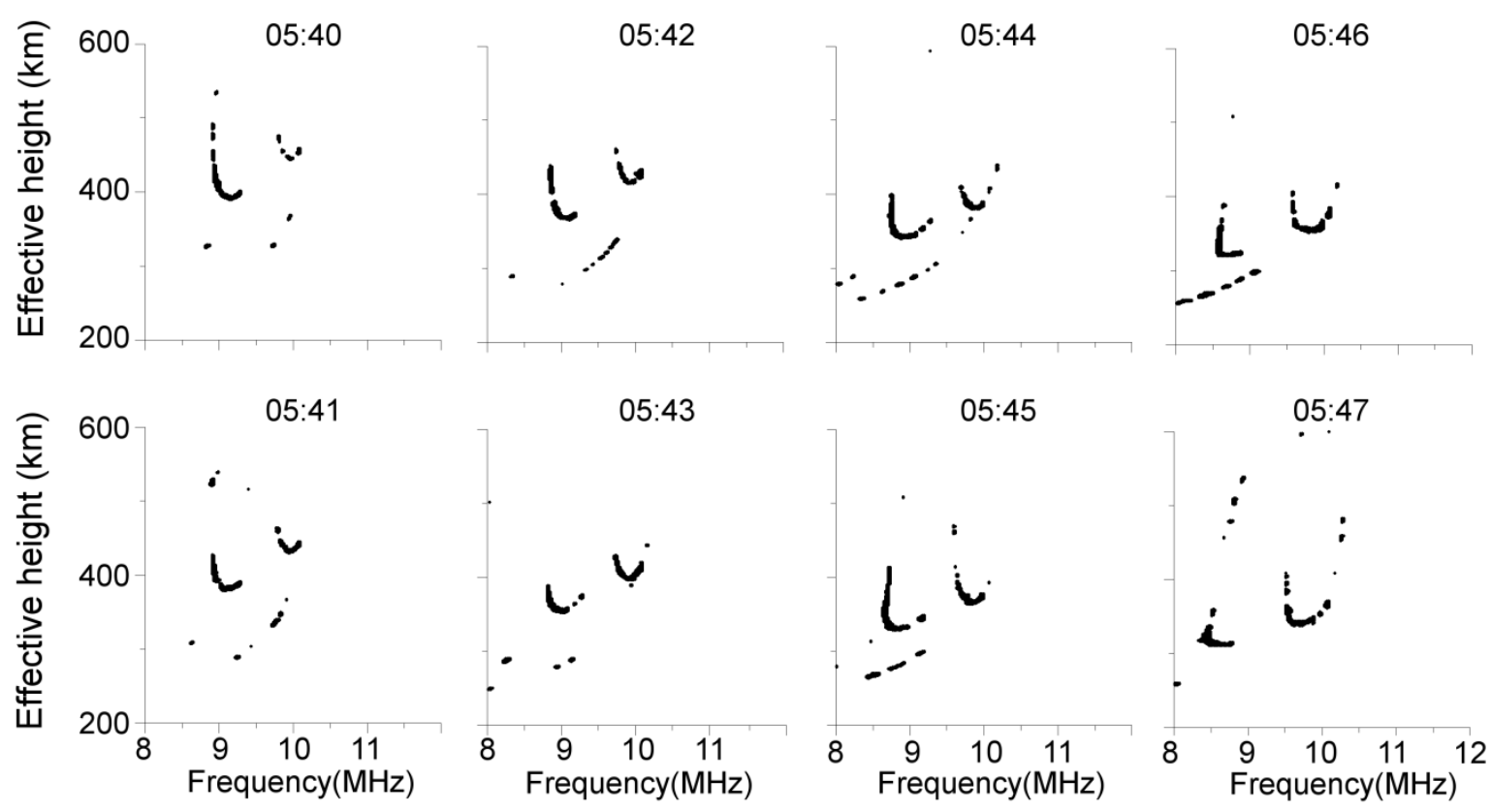

Figure 2. Ionograms obtained after filtering the ionograms presented in Figure 1

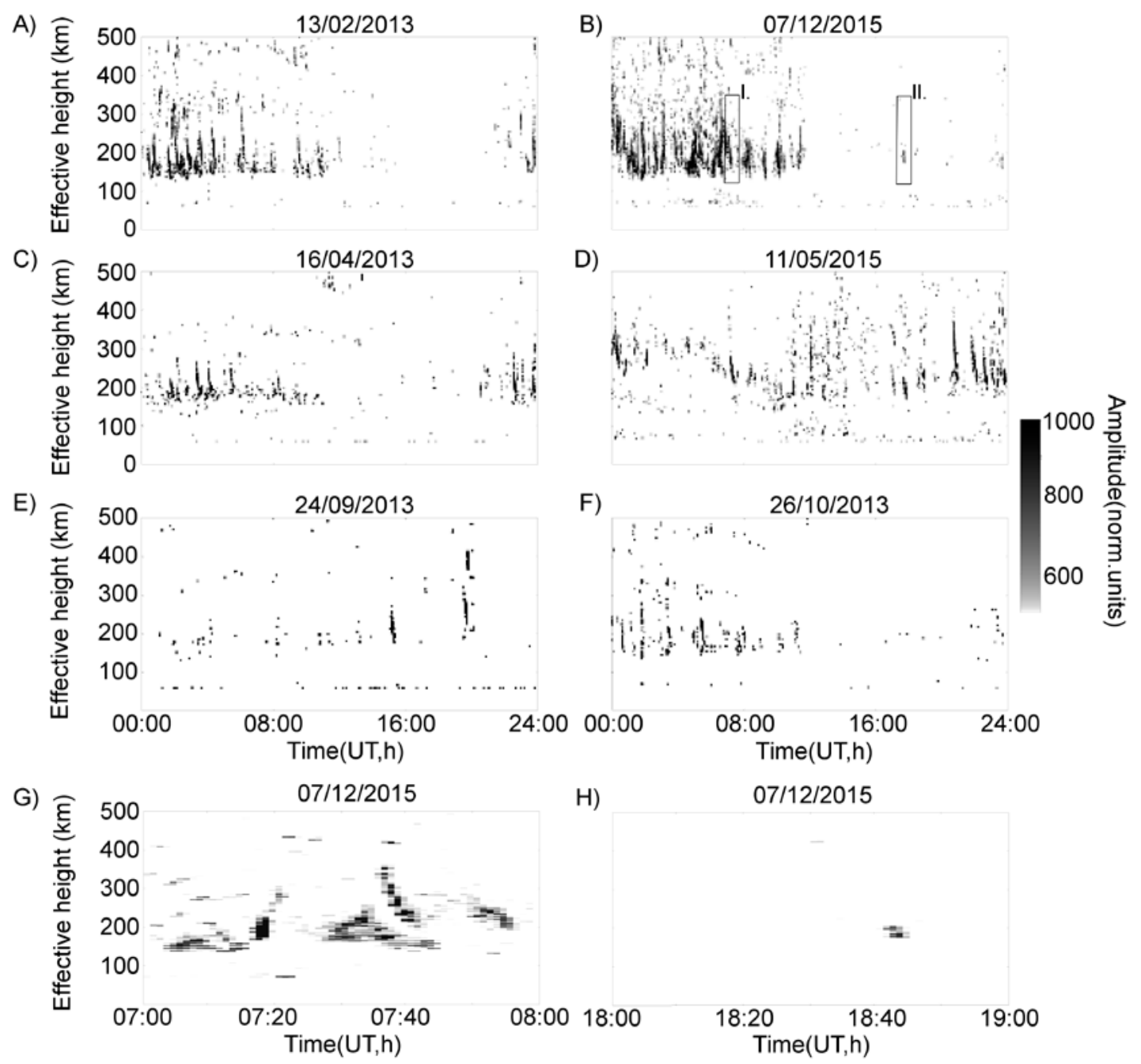

Figure 3. Manifestation of ionospheric irregularities on daily ionograms in different seasons: $a$, $b$ is winter (February 13, 2013, December 07, 2015); $c, d$ is spring (April 16, 2013, May 11, 2015); e, $f$ is autumn (September 24, 2013, October 26, 2013); areas I and II on panel $b$ are quasiperiodic and isolated disturbances respectively. Disturbances of different types: $g$ is a quasiperiodic disturbance (area I on panel $b$ ); $h$ is an isolated disturbance (area II on panel $b$ ) 
Figure 4 exemplifies the testing of the method using a sequence of manually and automatically processed ionograms with the above algorithm.

It can be seen (Figure 4) that the drift of the irregularity is nonlinear - at the top the velocity is higher than at the bottom. This is due to the fact that in uniform vertical drift of the irregularity near the F2-layer maximum, the group delay (effective height) increases nonlinearly with height. Nevertheless, in the lower ionosphere (where the effective height on the ionogram is approximately equal to the real height of reflection and the observed velocity is equivalent to the phase velocity in the vertical direction), we can consider the observed velocity of irregularity to be uniform in the first approximation and take the nonuniformity of the observed ve- locity at large heights only as a second-order correction.

To study the distribution of the observed vertical velocities of irregularities, we have automatically processed six days for three seasons, two days of winter (February 13, 2013, December 07, 2015), spring (April 16., 2013, May 11, 2015), and autumn (September 24, 2013, October 26, 2013). The results of this processing are shown in Figure 5.

As can be seen from the velocity distribution on the said days, there are two distinctly different distributions characteristic of all seasons: a wide velocity distribution with nearly $0 \mathrm{~m} / \mathrm{s}$ mean with a standard deviation of about $250 \mathrm{~m} / \mathrm{s}$ and a narrow velocity distribution with nearly $-160 \mathrm{~m} / \mathrm{s}$ mean.

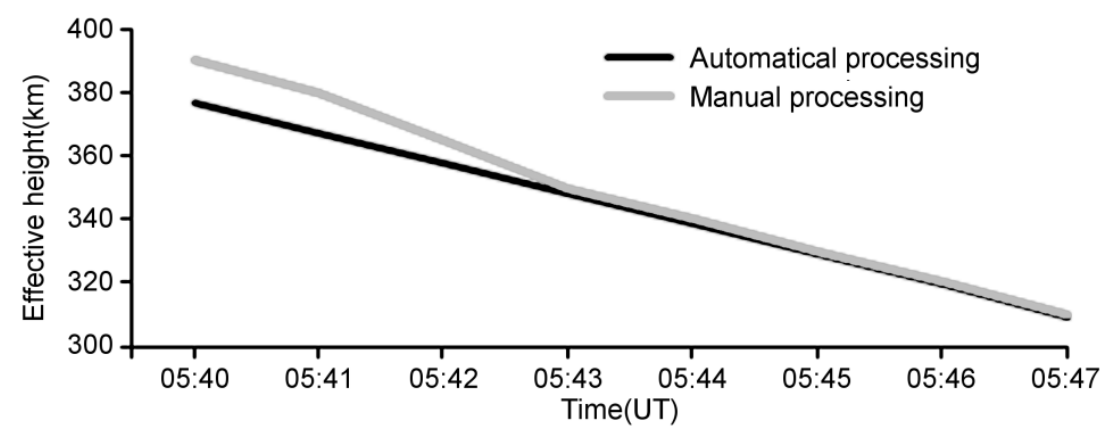

Figure 4. Dynamics of the effective height of reflection from an irregularity as a function of time on January 01, 2015, resulting from manual (gray line) and automatic (black line) processing
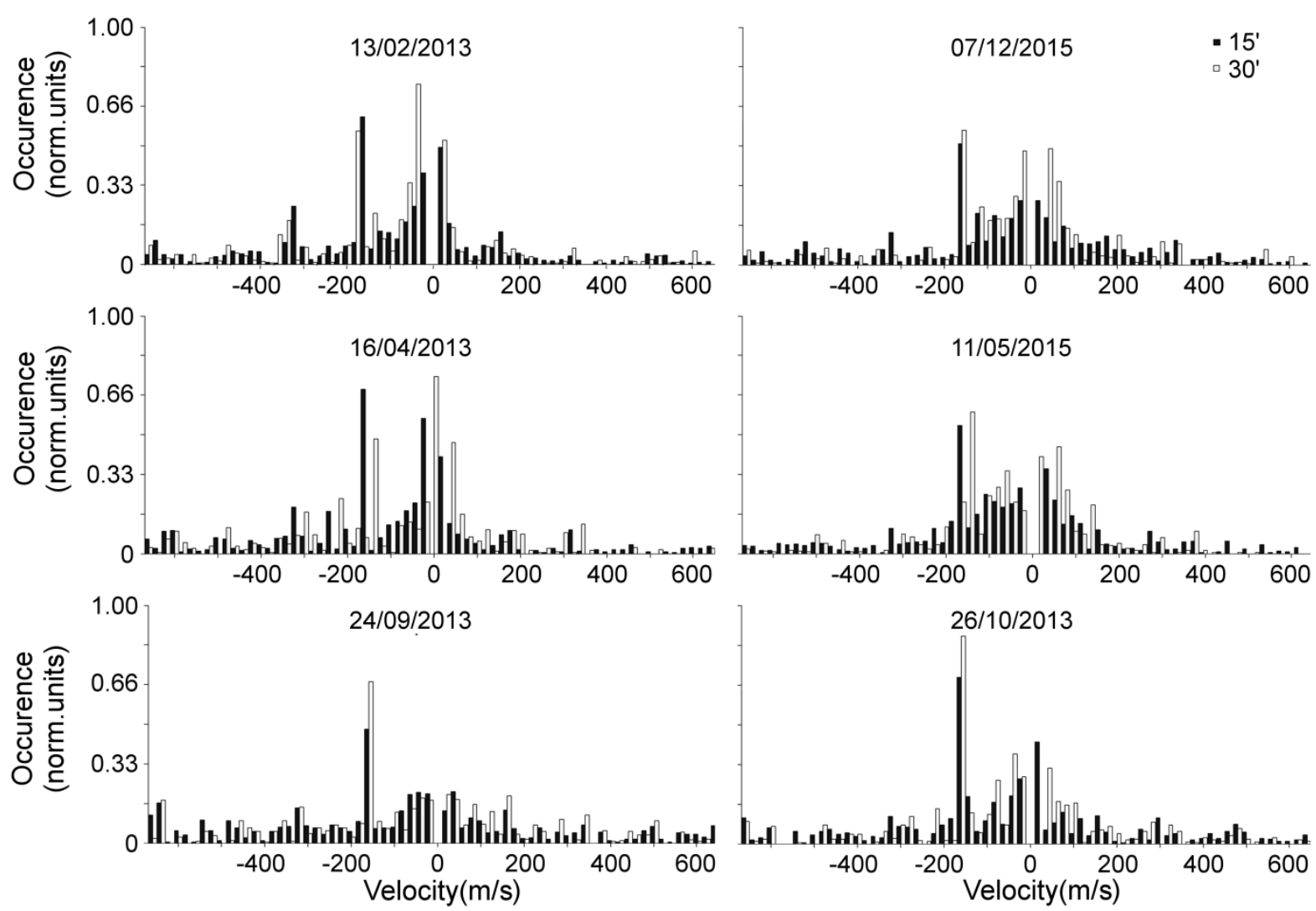

Figure 5. Seasonal distribution of irregularities by observed vertical velocities on different days: in winter (February 13, 2013, December 07, 2015), in spring (April 16, 2013, May 11, 2015), and in autumn (September 24, 2013, October 26, 2013). Colors correspond to filtering windows: black - 15 min; gray - 30 min 
Statistical parameters of velocity distribution after removing the peak at $-160 \mathrm{~m} / \mathrm{s}$ on different days

\begin{tabular}{|c|c|c|c|c|}
\hline Data & $\begin{array}{c}30 \text { min window, } \\
\text { average velocity, } \\
\mathrm{m} / \mathrm{s}\end{array}$ & $\begin{array}{c}30 \text { min window, } \\
\text { standard deviation } \\
\text { of velocity, m/s }\end{array}$ & $\begin{array}{c}15 \text { min window, } \\
\text { average velocity, } \\
\mathrm{m} / \mathrm{s}\end{array}$ & $\begin{array}{c}15 \text { min window, } \\
\text { standard deviation } \\
\text { of velocity, } \mathrm{m} / \mathrm{s}\end{array}$ \\
\hline February 13, 2013 & -67.8 & 234.8 & -76.3 & 264.7 \\
\hline December 07, 2015 & -15.6 & 225.5 & -27.8 & 283.8 \\
\hline April 16, 2013 & -89.6 & 249.8 & -89.5 & 245.5 \\
\hline May 11, 2015 & -59.8 & 184.4 & -50.2 & 339.1 \\
\hline $\begin{array}{c}\text { September 24, } \\
\text { 2013 }\end{array}$ & -30.3 & 306.2 & -62.7 & 299.1 \\
\hline October 26, 2013 & -33.1 & 261.5 & -33.3 & \\
\hline
\end{tabular}

The qualitative analysis of the ionograms confirms the presence of a large number of irregularities moving downward with close observed vertical velocities (Figure 1). To find causes for the observed effect, we have compared distributions of observed velocities of irregularities with two different maximal lifetimes $\Delta T_{0}-30$ and $15 \mathrm{~min}$. The results of the comparison are given in Figure 5 . The Figure shows that the form of the distributions is largely unrelated to the maximum lifetime used for estimating the velocity with our method. The observed features of the distribution are likely to be real and correspond to vertical phase velocities of irregularities.

Figure 5 indicates that the estimated velocity of $-160 \mathrm{~m} / \mathrm{s}$ has a rather narrow distribution with a width $\sim 10-20 \mathrm{~m} / \mathrm{s}$. The wide distribution of velocities has an average displacement of the order of $-50 \ldots-60 \mathrm{~m} / \mathrm{s}$ and a standard deviation of the order of $240-290 \mathrm{~m} / \mathrm{s}$. The smallness of the mean value in comparison with the standard deviation makes it possible in the first approximation to consider this distribution to be symmetric with zero mean and standard deviation of $\sim 250 \mathrm{~m} / \mathrm{s}$. The results of the statistical processing of the wide peak (after removing the narrow peak at $-160 \mathrm{~m} / \mathrm{s}$ ) for each of the days considered are presented in Table.

\section{CONCLUSION}

In the paper, we have described an algorithm for determining the observed vertical velocity of ionospheric irregularities with characteristic 1-15 min lifetimes on ionograms. The algorithm involves eliminating longlived (quasistationary) traces from ionograms and analyzing rapidly changing effects. The integral estimate of amplitude used in the algorithm and representing the frequency integration of a filtered ionogram allows us to evaluate the observed vertical velocity of irregularities, which in the first approximation may probably be interpreted as their vertical phase velocity. The analysis of six days of observations in different seasons (spring, winter, autumn) has shown that the observed vertical velocity of irregularities near Irkutsk features two characteristic distributions: a wide distribution of velocities near $0 \mathrm{~m} / \mathrm{s}$ with a standard deviation of about $250 \mathrm{~m} / \mathrm{s}$ and a narrow velocity distribution near $-160 \mathrm{~m} / \mathrm{s}$. The algorithm is implemented for ionograms obtained with the ISTP SB RAS fast chirp ionosonde for vertical sounding, and can be used to analyze data from other fast ionosondes.
The data used in this paper were obtained with the ISTP SB RAS fast chirp ionosonde (ISTP SB RAS Geophysical Observatory, the village of Tory), included in the Center for Common Use "Angara" facilities at ISTP SB RAS, under Project II.12.2.3 of Basic Research Program for 2013-2020. The work was partially supported by RFBR grant - Irkutsk region \# 17-45-388072 p_a. We are grateful to anonymous reviewers for useful comments.

\section{REFERENCES}

Berngardt O.I., Perevalova N.P., Dobrynina A.A., Kutelev K.A., Shestakov N.V., Bakhtiarov V.F., Kusonsky O.A., Zagretdinov R.V., Zherebtsov G.A. Toward the azimuthal characteristics of ionospheric and seismic effects of "Chelyabinsk" meteorite fall according to the data from coherent radar, GPS, and seismic networks. J. Geophys. Res.: Space Phys. 2015a, vol. 120 , no. 12 , pp. 10,754-10,771. DOI: $\underline{10.1002 /}$ 2015JA021549.

Berngardt O.I., Kotovich G.V., Mikhailov S.Ya., Podlesnyi A.V. Dynamics of vertical ionospheric inhomogeneities over Irkutsk during 06:00-06:20 UT 11/03/2011 caused by Tohoku earthquake. J. Atmos. Solar-Terr. Phys. 2015b, vol. 132, pp. 106-115. DOI: 10.1016/j.jastp.2015.07.004.

Berngardt O.I., Perevalova N.P., Podlesnyi A.V., Kurkin V.I., Zherebtsov G.A Vertical midscale ionospheric disturbances caused by surface seismic waves based on Irkutsk chirp ionosonde data in 2011-2016. J. Geophys. Res.: Space Phys. 2017. vol. 122, no. 4, pp. 4736-4754. DOI: 10.1002/2016JA023511.

Bilitza D., Altadill D., Truhlik V., Shubin V. International Reference Ionosphere 2016: from ionospheric climate to realtime weather predictions. Space Weather. 2017. vol. 15, no. 2. pp. 418-429. DOI: 10.1002/2016sw001593.

Frissell N.A., Baker J.B.H., Ruohoniemi J.M., Greenwald R.A., Gerrard A.J., Miller E.S., West M.L. Sources and characteristics of medium scale traveling ionospheric disturbances observed by high frequency radars in the North American sector. J. Geophys. Res.: Space Phys. 2016, vol. 121, no. 4, pp. 3722-3739. DOI: 10.1002/2015ja022168.

Givishvili G.V., Leshchenko L.N. Spatiotemporal parameters of anomalous reflections from the ionosphere. Geomagnetism and Aeronomy. 2017, vol. 57, no. 4, pp. 434441. DOI: $10.1134 /$ S0016793217040077.

Golikova E.V., Kunitsyn V.E., Matveyev A.S., Nesterov I.A. Modeling of the radio signal from the stratified atmosphere and ionosphere. Radiotekhnika i elektronika [J. of Communications Technology and Electronics]. 2005, vol. 50, no. 7, pp. 794-804. (In Russian). 
Haldoupis C.I., Meek C., Christakis N., Pancheva D., Bourdillon A. Ionogram height-time-intensity observations of descending sporadic E layers at mid-latitude. J. Atmos. SolarTerr. Phys. 2006, vol. 68, no. 3-5, pp. 539-557. DOI: 10.1016/ j.jastp.2005.03.020.

Hocke K., Schlegel K. A review of atmospheric gravity waves and travelling ionospheric disturbances: 1982-1995. Ann. Geophys. 1996, vol. 14, no. 9, pp. 917-940. DOI: $\underline{10.1007 /}$ s00585-996-0917-6.

Jiang Chunhua, Yuannong Zhang, Guobin Yang, Zhu Peng, Sun Hengqing, Cui Xiao, Song Huan, Zhao Zhengyu. Automatic scaling of the sporadic E layer and removal of its multiple reflection and backscatter echoes for vertical incidence ionograms. J. Atmos. Solar-Terr. Phys. 2015, vol. 129, suppl. C, pp. 41-48. DOI: 10.1016/j.jastp.2015.04.005.

Kozlovsky A., Turunen T., Ulich T. Rapid-run ionosonde observations of traveling ionospheric disturbances in the auroral ionosphere. J. Geophys. Res.: Space Phys. 2013, vol. 118, no. 8, pp. 5265-5276. DOI: $10.1002 /$ jgra.50474.

Kurkin V.I., Laryunin O.A., Podlesny V., Pezhemskaya M.D., Chistyakova L.V. Studying morphological characteristics of traveling ionospheric disturbances with the use of near-vertical ionospheric sounding data. Atmos. Ocean. Optics. 2014, vol. 27, no. 4, pp. 303-309. DOI: 10.1134/ $\underline{\mathrm{S} 1024856014040095 .}$

Liu J.-Y., Chen Ch.-H., Lin Ch.-H., Tsai H.-F., Chen Ch.H., Kamogawa M. Ionospheric disturbances triggered by the 11 March 2011 M9.0 Tohoku earthquake. J. Geophys. Res.: Space Phys. 2011, vol. 116, no. A6, A06319. DOI: 10.1029/2011ja016761.

Lobb R.J., Titheridge J.E. The effects of travelling ionospheric disturbances on ionograms. J. Atmos. Terr. Phys. 1977, vol. 39, pp. 129-138. DOI: 10.1016/00219169(77)90106-4.

Maruyama T., Tsugawa T., Kato H., Saito A., Otsuka Yu., Nishioka M.Ionospheric multiple stratifications and irregularities induced by the 2011 off the Pacific coast of Tohoku Earthquake. Earth, Planets, and Space. 2011, vol. 63, pp. 869873. DOI: $10.5047 /$ eps.2011.06.008.

Maruyama T., Yusupov K., Akchurin A. Interpretation of deformed ionograms induced by vertical ground motion of seismic Rayleigh waves and infrasound in the thermosphere. Ann. Geophys. 2016a. vol. 34, no. 2, pp. 271-278. DOI: 10.5194/angeo-34-271-2016.
Maruyama T., Yusupov K., Akchurin A. Ionosonde tracking of infrasound wavefronts in the thermosphere launched by seismic waves after the 2010 M8.8 Chile earthquake. J. Geophys. Res.: Space Phys. 2016b, vol. 121, no. 3, pp. 26832692. DOI: $10.1002 / 2015 j a 022260$.

Naumenko A.A., Podlesny A.V. Modernization of transmission and receiving facilities of chirp sounding network. Mezhdunarodnaya Baikalskaya molodezhnaya nauch shkola po fundamentalnoi fizike. Trudy XV konferetsii lodykh uchenykh. [Proc. Baikal Young Scientists' International School on Fundamental Physics. XV Young Scientists' Conference]. 2017, pp. 279-281. (In Russian).

Reinisch B.W., Galkin I.A., Khmyrov G.M. New digisonde for research and monitoring applications. Radio Sci. 2009, vol. 44, no. 1, RS0A24. DOI: 10.1029/2008rs004115.

Pignalberi A., Pezzopane M., Rizzi R., Galkin I.A. Effective solar indices for ionospheric modeling: a review and a proposal for a real-time regional IRI. Surv. Geophys. 2018, vol. 39, no. 1, pp. 125-167. DOI: 10.1007/s10712-017-9438-y.

Podlesny A.V. Chirp receiver using program systems. Mezhdunarodnaya Baikalskaya molodezhnaya nauchnaya shkola po fundamentalnoi fizike. Trudy XV konferetsii molodykh uchenykh. [Proc. Baikal Young Scientists' International School on Fundamental Physics. XV Young Scientists' Conference]. 2017, pp. 200-202. (In Russian).

Ponyatov A.A., Uryadov V.P., Ivanov V.A., Cherkashin Yu.N., Chernov A.G., Shumaev V. Oblique chirp sounding of the modified ionosphere. Experiment and simulation. Radiophys. Quant. Electron. 1999, vol. 42, no. 4, pp. 269-277. DOI: $10.1007 / \mathrm{bf02677569}$.

Toffoli T., Margolus N. Cellular Automata Machines: A New Environment for Modeling. Cambridge, MIT Press, 1987, 276 p.

Uryadov V.P., Kurkin V.I., Vertogradov G.G., Vertogradov V.G., Ponomarchuk S., Ponyatov A.A. Features of propagation of HF signals on mid-latitude paths under conditions of geomagnetic disturbances. Radiophys. Quant. Electron. 2004, vol. 47, no. 12, pp. 933-946. DOI: $10.1007 / \mathrm{s} 11141-005-$ 0035-4.

\section{How to cite this article}

Berngardt O.I., Bubnova T.V., Podlesnyi A.V. Automatic estimation of dynamics of ionospheric disturbances with 1-15 min lifetimes as derived from ISTP SB RAS fast chirp-ionosonde data SolarTerrestrial Physics. 2018, vol. 4, no. 1, pp. 64-70. DOI: 10.12737/stp41201807. 